\title{
Back to the Consideration of Future Consequences Scale: Time to Reconsider?
}

\author{
DAVID R. RAPPANGE \\ WERNER B.F. BROUWER \\ N. JOB A. VAN EXEL \\ Erasmus University Medical Center
}

\begin{abstract}
The Consideration of Future Consequences (CFC) Scale is a measure of the extent to which individuals consider and are influenced by the distant outcomes of current behavior. In this study, the authors conducted factor analysis to investigate the factor structure of the 12-item CFC Scale. The authors found evidence for a multiple factor solution including one completely present-oriented factor consisting of all 7 presentoriented items, and one or two future-oriented factors consisting of the remaining futureoriented items. Further evidence indicated that the present-oriented factor and the 12-item CFC Scale perform similarly in terms of internal consistency and convergent validity. The structure and content of the future-oriented factor(s) is unclear. From the findings, the authors raise questions regarding the construct validity of the CFC Scale, the interpretation of its results, and the usefulness of the CFC scale in its current form in applied research.
\end{abstract}

Keywords: consideration of future consequences, individual behavior, time preference

THE CONSIDERATION OF FUTURE CONSEQUENCES in current behavior is increasingly acknowledged as being important, as the effects that current behaviors and attitudes may have on future wellbeing and health can be profound. The tradeoff between satisfying immediate desires and future benefits is therefore a matter of concern in areas like healthcare (smoking, unsafe sex), environment (exhausting resources), and finance (savings and pension building). Whether individuals take these possible distant outcomes into consideration when deciding to engage in certain behaviors, or just focus on maximizing their immediate benefits without regarding future consequences, is often considered to be a more or less stable and measurable personal characteristic.

Address correspondence to David R. Rappange, Department of Health Policy \& Management, Institute for Medical Technology Assessment, Erasmus University Medical Center, P.O. Box 1738, 3000DR, Rotterdam, The Netherlands; rappange@bmg.eur.nl (e-mail). 
Following initial studies on time perspective by Frank (1939) and Lewin (1942), several researchers (e.g., DeVolder \& Lens, 1982; Fraisse, 1963; Kastenbaum, 1961; Lamm, Schmidt, \& Trommsdorff, 1976; Nuttin, 1964; Wallace, 1956) have examined the concept of what has been labeled future time perspective in the second half of the last century. Although slightly different definitions of this concept have been used, it is generally defined as "a rather generalized concern for future events and experiences" (Kastenbaum, 1961, p. 213). Despite attempts to develop instruments that measure this general concern with the future adequately, researchers have not yet achieved satisfying results in terms of consistency, reliability, and validity (for a review, see Strathman, Gleicher, Boninger, \& Edwards, 1994).

Strathman et al. (1994) developed the Consideration of Future Consequences (CFC) Scale, a measure for assessing individual differences in this construct of future thought. Given the complexity of the concept this instrument attempts to capture, this warrants a careful consideration of its construct validity. However, after the first study by Strathman et al., only Petrocelli (2003) has examined the factor structure of the CFC Scale. Contrary to Strathman et al., Petrocelli found evidence of two underlying factors, and hence suggested that an adjusted version of the CFC Scale would be a better measure of the CFC construct. So far, however, supporting evidence for this claim is lacking.

Meanwhile, as highlighted further below, the CFC appears to be increasingly used in applied research in different contexts as a measure of consideration of future consequences. This makes it more important to address the questions regarding the underlying factor structure of the CFC scale. Therefore, in this article, we present the results of a study that elaborated on the two previous studies regarding the properties of the CFC scale, and that aimed at providing additional evidence in the factor validation process of the CFC Scale. Moreover, we examine the feasibility of the scale in young adolescents; the convergent validity of the scale - and possible underlying factors - with alternative measures assessing adolescents' appreciation and expectations of their future; and the relation of the scale with several personal characteristics.

\section{Consideration of Future Consequences}

Strathman et al. (1994) tried to assess a unique aspect of the future time perspective and not merely a general preoccupation with the future. Strathman et al. (1994) described the CFC as follows:

The CFC refers to the extent to which individuals consider the potential distant outcomes of their current behaviors and the extent to which they are influenced by these potential outcomes. It involves the intrapersonal struggle between present behavior with one set of immediate outcomes and one set of future outcomes. (p. 743)

The CFC Scale consists of 12 items measured on a Likert-type scale ranging from 1 (extremely uncharacteristic) to 5 (extremely characteristic), of which 
seven items should be reverse-scored to obtain a total score ranging from 12 to 60 (or mean scores ranging from 1 to 5). A higher score indicates a higher level of consideration of future consequences (for original instrument and instructions see www.missouri.edu/ psyas/cfc.pdf). Individuals high in CFC are expected to focus more on the future implications of their behavior and to use these as a guide for their current behaviors. In extreme cases, these individuals may completely disregard immediate outcomes in their decision making process. On the other hand, individuals low in CFC are expected to focus more on immediate needs and concerns, and their actions are expected to be focused on meeting these immediate needs. At the extreme end, these individuals do not take future consequences into account at all (Strathman et al., 1994).

To provide evidence of the influence of CFC on behaviors and attitudes, Strathman et al. (1994, Experiment 1) showed the effect of the CFC construct on information processing by demonstrating that individuals high in CFC, because of their greater interest in the environment, were less in favor of increased offshore oil drilling. More important, high CFC individuals were more in favor of oil drilling when its advantages were framed in the future and its disadvantages in the present. Conversely, low CFC individuals were more in favor of oil drilling when the advantages were outlined as immediate and disadvantages as distant. These results suggest that the time frame in which the consequences are portrayed has a greater influence on the decision-making process of individuals as opposed to whether the outcomes are either positive or negative.

In a second experiment, Strathman et al. (1994, Experiment 2) demonstrated that the CFC Scale accounts for unique variance in behavior over and above other measures assessing individual differences, including the Stanford Time Perspective Inventory (Gonzalez \& Zimbardo, 1985; Zimbardo, 1990), for example in cigarette use and general health concern.

The CFC Scale has been used in several studies in various research areas. For example, researchers have demonstrated that individuals high in CFC, as compared to individuals low in CFC, are more likely to engage in proenvironmental consumer behavior (Joireman, Van Lange, \& Van Vugt, 2004; Lindsay \& Strathman, 1997), proenvironmental political behavior (Joireman, Lasane, Bennett, Richards, \& Solaimani, 2001), safe sexual behavior, and HIV testing (Dorr, Krueckeberg, Strathman, \& Wood, 1999). Orbell, Perugini, and Rakow (2004) reported that individuals high in CFC were more in favor of participating in colorectal cancer screening, and Orbell and Hagger (2006) found similar results with regard to Type 2 diabetes screening. In addition, researchers have demonstrated that high CFC individuals have higher academic achievement (Joireman, 1999) and tend to have greater fiscal responsibility (Joireman, Sprott, \& Spangenberg, 2005). Joireman, Anderson, and Strathman (2003), moreover, found evidence of a link between CFC and aggression, while Insko et al. (1998) demonstrated that a higher CFC among members of different groups diminishes intergroup competitiveness. However, this latter finding is not supported by Insko et al. (2001). 


\section{Factor Validation of the Consideration of Future Consequences Scale}

Strathman et al. (1994) started with a set of 24 statements when developing the CFC Scale and conducted exploratory and confirmatory factor analysis to assess its factor structure. The results of both exploratory and confirmatory factor analysis provided evidence for a one-factor solution consisting of 12 items that measured the CFC construct best. Strathman et al. demonstrated that these 12 items, together named the CFC Scale, were reliable in terms of internal consistency (Cronbach's $\alpha$ 's between .80 and .86) and stability over time (e.g., test-retest correlation of .72). In addition, relationships between the CFC Scale and other measures evidenced a good convergent validity, for example, between the CFC Scale and future orientation (e.g., Strathman et al., 1994; Zimbardo \& Boyd, 1999), delay of gratification, and conscientiousness (Strathman et al., 1994).

Its extensive use in a wide variety of studies, the inconsistent results regarding the association between CFC and intergroup competitiveness, and the modest amount of empirical validation, induced Petrocelli (2003) to examine the factor structure of the CFC Scale in more detail. First, Petrocelli explored the factor structure of the CFC scale by means of principal component analysis resulting in two underlying factors. Subsequently, Petrocelli used confirmatory factor analysis to examine four maximum likelihood solutions. Petrocelli attained a Cronbach's alpha coefficient of only .48 for Factor 2 (as opposed to .82 for Factor 1), and a relatively low correlation between the two factors $(r=.54)$ despite the fact that it concerns items from the same scale. Hence, Petrocelli suggested that the two underlying factors might be assessing different constructs: Factor 1 focused almost exclusively on immediate behavior and immediate consequences, and Factor 2 concerned distant consequences of immediate behavior. Petrocelli also evaluated a model composed of one factor containing all the reverse-scored items and Item 2. Petrocelli found that this model, omitting items of Factor 2, produced the best fit and therefore proposed that an 8-item version of the CFC Scale, consisting of almost exclusively reverse-scored items, might be a more appropriate measure of the CFC construct. Petrocelli concluded that the CFC Scale may not so much be a measure of the extent to which individuals consider future consequences of their behavior, but more of the extent to which they are not influenced by immediate consequences of their actions-that is, if the reverse-scored items are in fact reverse scored. Otherwise, these items could serve as a measure of the extent to which people are influenced by the immediate consequences of their actions.

\section{Study Hypotheses}

Since the participants who completed the questionnaire in the present study are exclusively young adolescents, we assessed the feasibility of the CFC Scale in this study sample first. Although some authors have reported evidence of equal competency in decision-making between adolescents and adults (e.g., Quadrel, 
Fischhoff, \& Davis, 1993), several authors have found that young adolescents are less able to foresee consequences of new alternatives and less able to conceptualize risks and benefits of their actions (e.g., Kaser-Boyd, Adelman, \& Taylor, 1985; Lewis, 1981; Mann, Harmoni, \& Power, 1989). Others have supported this notion of immaturity of judgment among young adolescents as opposed to older adolescents (Cauffman \& Steinberg, 2000; Steinberg \& Cauffman, 1996), while van Exel, De Graaf, and Brouwer (2006) theorized that adolescents would only consider their future to a very limited extent. Therefore, a lower mean CFC score is expected in the present study sample, as compared to results from other studies, and potentially a poor feasibility.

The general study hypothesis concerned the factor structure of the CFC Scale. Petrocelli (2003) reported multiple underlying factors, therefore we hypothesized that the CFC Scale decomposes in two or more underlying factors. In order to clarify this further, we explored the convergent validity of the CFC Scale. We expected that the CFC Scale would correlate (positively) with other measures that assess young adolescents' appreciation and expectations of their future, as well as with health belief statements. However, the correlations between these measures and any underlying factors of the CFC Scale could be different. We also investigated this.

Finally, we investigated associations of the CFC scale and any underlying factors with several personal characteristics. In past research, variables including sex, educational level, and personality have discriminated between individuals high and low in CFC. Contradictory results have been reported concerning sex. Petrocelli (2003) found that men scored significantly lower on the 12-item CFC Scale than women. Similar sex differences were found in the first factor of the two-factor solution, but not in Factor 2. Other researchers (e.g., Orbell \& Hagger, 2006) found no significant differences in scores in CFC between men and women. No hypothesis is made here. Based on a study by Joireman (1999) concerning academic achievement, a higher score in CFC is expected to correlate with a higher education. Other researchers have reported a correlation between CFC and Goldberg's conscientiousness dimension (e.g., Insko et al., 1998; Orbell \& Hagger, 2006; Strathman et al., 1994). Associations with all Big Five personality dimensions are investigated. Finally, we tested the discriminative power for religious upbringing, Body Mass Index (BMI), health status, happiness, and attitudes about health lifestyle.

\section{METHOD}

\section{Participants}

We conducted secondary analysis on existing data of 2,006 young adolescents (1,064 girls and 942 boys) recruited in May 2005 from 10 secondary education schools throughout the Netherlands. van Exel, Koolman, De Graaf, and 
Brouwer (2006) obtained the sample in a study investigating adolescents' health behavior in relation to their attitudes about their health lifestyle and their consideration of the future consequences of their behavior. Participants between the ages of 11 to 15 (mean age $=13.2$ years, $S D=0.70$ ) attended either 1 st or 2 nd grade of pre-vocational or general secondary education. The vast majority of the study sample was autochthonous Dutch (90.1\%).

\section{Materials}

Participants completed the "Health \& Future" questionnaire during class, under supervision of their teacher. The questionnaire covered eight topic areas: about you, about your health, about your future, about home, about school, about your leisure time, about what you eat, and about money. The about your future section included the CFC Scale and some alternative measures assessing future appreciation and expectations. We translated the CFC Scale into Dutch and slightly simplified the wording to increase its comprehensiveness for young adolescents (see Appendix).

We assessed personality using a short version of Goldberg's Big Five Personality Inventory (Gerris et al., 1998; Goldberg, 1992). We asserted health status using a visual analogue scale ranging from 0 (worst conceivable health state) to 10 (best conceivable health state) and happiness using a visual analogue scale ranging from 0 (completely unhappy) to 10 (perfectly happy). We further assessed attitude about health lifestyle by means of self-categorization to one of five attitudes identified within the same population before using Q-methodology: carefree sporty, worrying dependent, contended independent, looks over content, and indifferent solitary (van Exel, De Graaf, et al., 2006). For a more detailed discussion of the sample method, questionnaire development and contents, and measures used, see van Exel, Koolman, et al. (2006).

\section{Procedure}

First of all, we made a straightforward comparison of the descriptive statistics (scores on the CFC Scale) of the present study sample with the results from several other studies.

\section{Feasibility}

We asserted the feasibility of the CFC Scale in this sample by means of response analysis, i.e., in terms of the percentage of completed scales with no missing items, the percentage of completed scales with no more than $10 \%$ missing items, the percentage of missing values per item, and the standardized index of missing values. The standardized index is computed by dividing the mean number of missing values per respondent by total number of items, multiplied by 100 
(Essink-Bot, Krabbe, Bonsel, \& Aaronson, 1997). We excluded completed CFC scales with more than $10 \%$ missing items (that is, more than one missing item) from further analyses. In case of a single missing item, the average score of the respondent on the other 11 items replaced the missing item, after recoding the reverse scored items.

\section{Reliability}

We analyzed the reliability of the CFC scale by assessing its internal consistency using two indicators: Cronbach's alpha coefficient and item-total correlation.

\section{Factor Analysis}

We used factor analysis to assess the interrelationship among the scale items and to identify the number of underlying dimensions. First, we tested the factorability of the CFC data. We computed the determinant value of the correlation matrix to test for multicollinearity or singularity. This value should be greater than .00001 (Field, 2005; Pett, Lackey, \& Sullivan, 2003). Next, we performed Bartlett's Test of Sphericity (Bartlett, 1950) and Kaiser-Meyer-Olkin's (KMO) test of sampling adequacy (Kaiser, 1970, 1974). To allow factor analysis, the first test should be significant $(p<.05)$, while the size of the KMO value should exceed .60 (Tabachnick \& Fidell, 2001). If all these tests are shown to be satisfactory, the data is suitable for factor analysis.

The actual factor analysis consisted of two phases. First, we subjected the CFC Scale to confirmatory factor analysis via the maximum likelihood method of estimation, using the factor solutions reported by Strathman et al. (1994) and Petrocelli (2003). We evaluated two models: first, the solution of Strathman et al., which consisted of one factor including all 12 items; second, the two-factor solution of Petrocelli, consisting of Factor 1 (Item 2, 3, 4, 5, 9, 10, 11, and 12) and Factor 2 (Item 1, 6, 7, and 8). To determine whether the number of extracted factors in both models was adequate, we computed two common goodness-of-fit tests: the chi-square $\left(\chi^{2}\right)$ test and the ratio of the chi-square to its degrees of freedom $\left(\chi^{2} / d f\right)$. The advantage of the $\chi^{2} / d f$ ratio over the $\chi^{2}$ index is its insensitivity to large sample sizes, but there is some indistinctness in the literature about what cutoff point for the $\chi^{2} / d f$ ratio we should use to achieve an "adequate fit." We used the 5:1 ratio suggested by Wheaton, Muthen, Alwin, and Summers (1977).

In the second phase, we conducted exploratory analysis on the present data set, namely principal component analysis with Varimax rotation. To assert the number of factors to retain, we used three techniques, of which the Kaiser's criterion (e.g., Kaiser, 1960) is the most commonly used, also known as the eigenvalue rule. Only factors with an eigenvalue greater than 1.0 are retained. This technique has been criticized in the past, as it tends to overestimate the number of factors to select (e.g., Zwick \& Velicer, 1986). Next, we performed Catell's 
(1966) scree test, which implies inspection of the scree plot in which the extracted factors are plotted against their eigenvalues. The final approach, Horn's Parallel Analysis (Horn, 1965), involves the comparison of the eigenvalues with eigenvalues obtained from a randomly generated data set of the same size. This technique is considered to be the most accurate (Zwick \& Velicer, 1986) and we used Watkins (2000) to conduct this test.

\section{Convergent Validity}

We assessed the convergent validity through Spearman's rank-order correlation of the CFC Scale and any underlying factors with alternative measures assessing adolescents' appreciation and expectations of their future and some health belief statements. We asked respondents (A) how important it was to them what their life would be like 2, 5, and 25 years from now (Likert-type scale, four levels ranging from very important to not at all important); (B) to make a series of trade-offs between money values now and in the future (2, 5, and 25 years from now), which were used to calculate discount rates; $(\mathrm{C})$ to consider $3 \times 2$ investments in health (improve their dietary behavior, exercise 30 minutes more per day, and take an injection that would make them sick for the next week) that would yield (i) a better health at age 70 or (ii) extend life with 3 years; (D) for their subjective life expectancy; (E) for their expectations regarding their health status at the age of 40 and 70; and $(\mathrm{F})$ to evaluate seven health belief statements. To ensure that higher scores indicated higher appreciation of the future, we reversed the scores for Measure A, B, C, and F. We interpreted the strength of the relationship according to the guidelines suggested by Cohen (1988): $r \mathrm{~s}=.10$ to .29 indicates a small, $r \mathrm{~s}=.30$ to .49 a medium, and $r \mathrm{~s}=.50$ to 1.0 a large correlation effect size.

\section{Relation With Personal Characteristics and Health Variables}

Finally, we used $t$ tests, one-way between-groups ANOVA with Tukey's post hoc test, and Spearman's rank-order correlation to explore associations of the CFC and any underlying factors with personal characteristics and several health variables. We assessed the strength of the relationships found using the $t$ tests using Cohen's $d$ (i.e., $d=0.20$ indicates a small, $d=0.50$ a medium, and $d=0.80$ a large effect).

\section{RESULTS}

We received completed questionnaires from 2,006 young adolescents residing in the Netherlands. Averaged individual mean scores on the 12-item CFC Scale ranged from 1.33 to 4.75 . The average score in the present study sample was $3.27(S D=0.50)$, and the median was 3.33 . This is similar to a recent Dutch 
academic sample collected by Rappange (2005, $M=3.28)$ and to mean scores reported among samples of 50- to 69-year-olds (Orbell \& Hagger, 2006; Orbell et al., 2004). In contrast, Strathman et al. (1994) and Petrocelli (2003) reported mean scores around 3.50 in academic settings. Our findings are inconsistent with our expectation that young adolescents would score lower on the CFC Scale.

We further anticipated that the feasibility of the CFC Scale in this study sample might be poor. However, we found excellent results on all measures of feasibility. In total, we received 1946 (97\%) scales without missing values. Only 9 out of 2,006 completed questionnaires had more than $10 \%$ missing values on the CFC Scale, which we therefore excluded from further analyses. Missing values per item ranged from $0.1 \%$ to $0.6 \%$, and the standardized index of missing values was 0.4 .

We assessed the internal consistency to investigate the reliability of the CFC Scale. Cronbach's alpha coefficient for the scale was .76, and item-total correlations ranged from .26 to .58 . Both values are similar to results from previous studies.

\section{Factor Analysis}

Preceding the evaluation of the different factor solutions found by Strathman et al. (1994) and Petrocelli (2003), we assessed the suitability of the dataset for factor analysis. The determinant value was .130, the Barlett's Test of Sphericity reached significance, $\chi^{2}=4068.430, p<.01, d f=66, N=1997$, and the KMO value was .830, which meets Kaiser's (1974) "meritorious" criteria. All tests support the factorability of the data.

\section{Confirmatory Factor Analysis}

Evaluation of the one-factor structure reported by Strathman et al. (1994) and the two-factor structure by Petrocelli (2003), using confirmatory factor analysis, resulted in unsatisfactory results. Factor loadings on the one-factor solution ranged from .224 to .710 . The model did not produce an adequate fit, $\chi^{2}$ (54, $N=1997)=804.95, p<.01$ and $\chi^{2} / d f=14.91$. This exceeds the $5: 1$ ratio proposed by Wheaton et al. (1977). The two-factor model also produced a poor fit, $\chi^{2}(43, N=1997)=435.37, p<.01$ and $\chi^{2} / d f=10.12$. The factor pattern matrix and the factor structure matrix of this model, together with the item descriptives, are shown in Table 1. In absence of satisfactory results, we conducted additional exploratory factor analysis to explore more appropriate factor structure solutions.

\section{Exploratory Factor Analysis}

Principal components analysis with Varimax rotation resulted in three factors with eigenvalues greater than 1.0 , explaining a total of $49.0 \%$ of the variance 


\section{TABLE 1. Item Descriptives and Factor Pattern/Structure Matrix of the Consideration of Future Consequences Scale: Maximum Likelihood With Direct Oblimin Rotation $(\delta=-\mathbf{0 . 5 0})$}

\begin{tabular}{|c|c|c|c|c|c|c|}
\hline \multicolumn{3}{|c|}{ Item descriptives } & \multicolumn{2}{|c|}{ Factor pattern matrix } & \multicolumn{2}{|c|}{ Factor structure matrix } \\
\hline Item & $M$ & $S D$ & Factor 1 & Factor 2 & Factor 1 & Factor 2 \\
\hline 1 & 3.36 & 0.97 & .169 & .603 & .365 & .658 \\
\hline 2 & 2.56 & 0.99 & -.023 & .562 & .159 & .555 \\
\hline $3^{\mathrm{a}}$ & 2.91 & 1.08 & .587 & .138 & .632 & .328 \\
\hline $4^{\mathrm{a}}$ & 2.76 & 0.96 & .522 & -.005 & .520 & .164 \\
\hline $5^{\mathrm{a}}$ & 3.55 & 0.95 & .329 & -.016 & .324 & . \\
\hline 6 & 3.64 & 0.89 & .306 & .172 & .362 & .271 \\
\hline 7 & 3.80 & 0.93 & .317 & .169 & .372 & .272 \\
\hline 8 & 3.43 & 0.92 & .241 & .248 & .321 & .326 \\
\hline $9^{\mathrm{a}}$ & 2.27 & 0.99 & .626 & -.084 & .599 & .119 \\
\hline $10^{\mathrm{a}}$ & 2.53 & 0.97 & .543 & .013 & .547 & .189 \\
\hline $11^{\mathrm{a}}$ & 2.36 & 0.96 & .762 & -.064 & .742 & .183 \\
\hline $12^{\mathrm{a}}$ & 3.12 & 0.90 & .388 & -.086 & .360 & .039 \\
\hline
\end{tabular}

Note. Item means and standard deviations are before reverse-scoring. Loadings in bold are values greater than .30 and are retained for that factor. Underlined values indicate a multiple loading on two factors. Eigenvalues for Factor 1 and Factor 2 are 2.743 and 0.650 , respectively (before rotation). The two-factor solution explains a total amount of $28.3 \%$ of the variance, with Factor 1 contributing 22.9\% and Factor 2 contributing 5.4\% (before rotation). Factor 1 and Factor 2 are correlated $(r=.32)$.

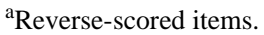

with the three factors accounting for $20.8 \%, 16.4 \%$, and $11.9 \%$, respectively. The factor loadings of all items on the three factors are shown in Table 2. Inspection of the scree plot revealed a break after the third factor, and this was further supported by the results Parallel Analysis provided, which showed three eigenvalues exceeding the corresponding eigenvalues from the generated data (12 variables $\times$ 1997 subjects). Next, principal components analysis with Direct Quartimin rotation $(\delta=0)$ showed that the correlation between the three factors ranged from .09 to .27 . The absence of strong relations among any combination of two factors justifies the use of Varimax rotation (Field, 2005; Pett et al., 2003). In addition, we performed reliability analysis for all factors. Factor A1 (Item 3-5 and 9-12) scored well in terms of internal consistency (Cronbach's $\alpha=.74$ ). We found lower Cronbach's alpha coefficients (.52 and .54) for Factor A2 (Item 6-8) and Factor A3 (Item 1-2), respectively. The respondents scored higher on Factor A2 $(M=3.62, S D=0.66)$, as compared to Factor A1 $(M=3.21, S D=0.61)$ and Factor A3 $(M=2.96, S D=0.81)$. Factor A1 turned out to consist of the seven reverse-scored items, and Factors A2 and A3 of the positively worded items. Although the three-factor solution indicates a clear statistical distinction between 


\section{TABLE 2. The Factor Loading Matrix of the Consideration of Future Consequences Scale: Principal Components Analysis With Varimax Rotation}

\begin{tabular}{|c|c|c|c|c|}
\hline \multirow[b]{2}{*}{ Item } & \multicolumn{3}{|c|}{ Factor } & \multirow[b]{2}{*}{ Communality } \\
\hline & A1 & $\mathrm{A} 2$ & A3 & \\
\hline $4^{\mathrm{a}}$ & .713 & -.019 & .174 & .539 \\
\hline $3^{\mathrm{a}}$ & .662 & .189 & .299 & .563 \\
\hline $11^{\mathrm{a}}$ & .647 & .418 & -.005 & .594 \\
\hline $5^{\mathrm{a}}$ & .575 & -.175 & .153 & .385 \\
\hline $9^{\mathrm{a}}$ & .523 & .461 & -.136 & .505 \\
\hline $10^{\mathrm{a}}$ & .488 & .402 & -.004 & .400 \\
\hline $12^{\mathrm{a}}$ & .478 & .124 & -.100 & .254 \\
\hline 8 & -.027 & .692 & .186 & .515 \\
\hline 7 & .118 & .636 & .059 & .422 \\
\hline 6 & .102 & .601 & .149 & .393 \\
\hline 2 & .023 & .059 & .839 & .707 \\
\hline 1 & .163 & .295 & .701 & .605 \\
\hline Eigenvalue & 2.490 & 1.966 & 1.427 & 5.877 \\
\hline$\%$ of variance & 20.8 & 16.4 & 11.9 & 49.0 \\
\hline
\end{tabular}

Note. Loadings in bold are values greater than .40 and are retained for that factor. Underlined values indicate a multiple loading on two factors. Eigenvalues and percentage of variance are after rotation.

${ }^{\text {a }}$ Reverse-scored items.

Factors A2 and A3, a closer examination of the content of these items and an attempt to interpret both factors did not result in a comparable clear-cut distinction between the two factors. Moreover, both factors independently did not prove to be very stable. Therefore, we also included a two-factor solution consisting of Factor B1 (identical to A1) and Factor B2 (A2 and A3 combined; Cronbach's $\alpha=.59$; $M=3.36, S D=0.58)$ in further analyses.

\section{Convergent Validity}

Table 3 presents the correlations between the CFC Scale, underlying factors, and six other measures assessing appreciation of the future. We found small positive correlations for the CFC Scale and underlying factors with importance of future life (Measure A) and health expectancy at age 40 and 70 (Measure E). Correlations with adolescents' discount rates (Measure B) were also small and decreased substantially when the trade-offs between money now and later involved longer delays. This may indicate that adolescents' time horizon when thinking about future outcomes is fairly limited, or that the CFC predominantly captures mid-term (2-5 years) outcomes in adolescents. Regarding the health 


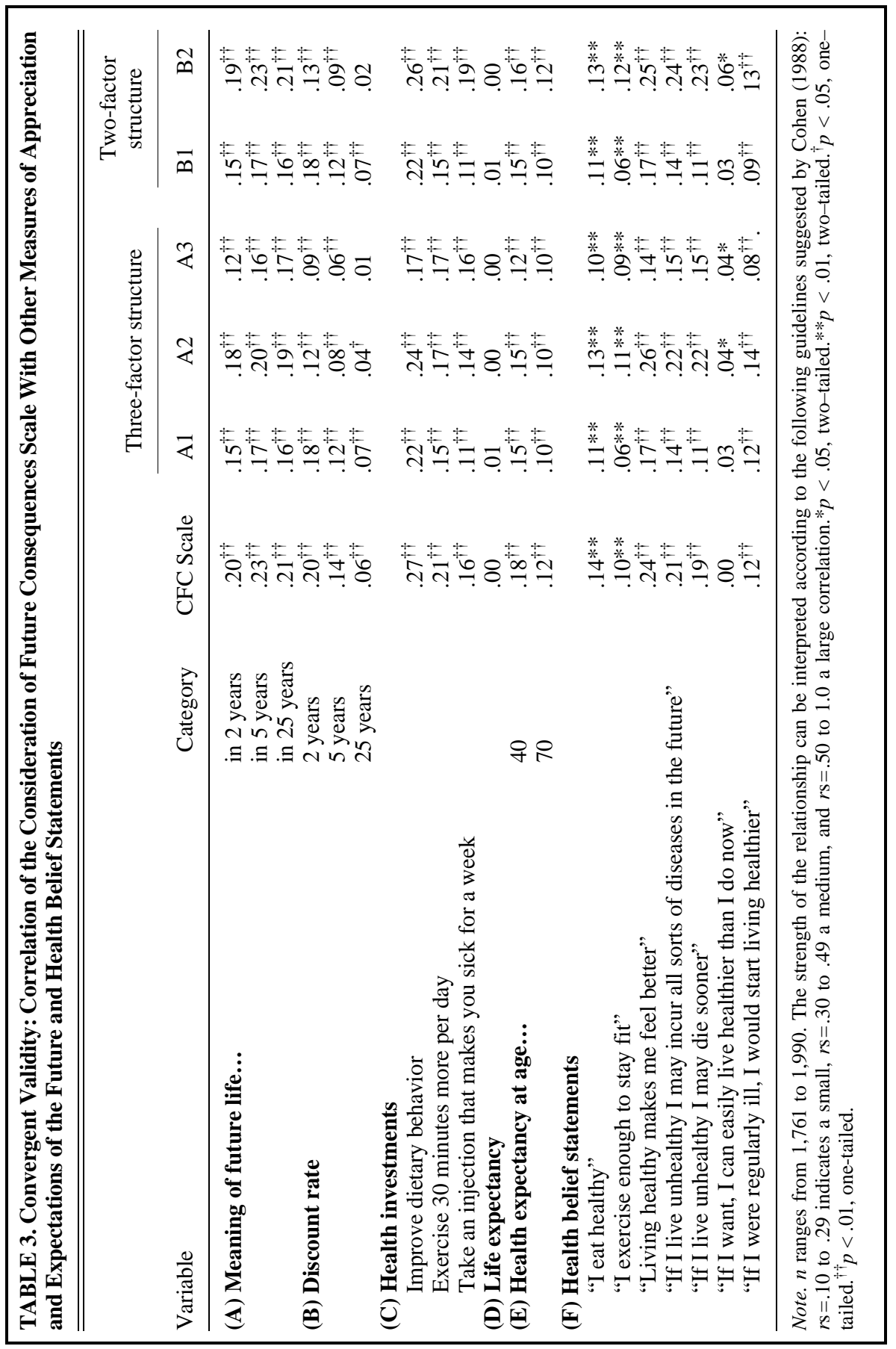


investments (Measure C), we found higher correlations for improving dietary behavior than for the other two investments, and - not shown in the table- for investments that would yield a better health at age 70 rather than extending life by three years. This applied to the CFC Scale as well as to the underlying factors. We found no correlation with life expectancy (Measure D), while correlations with the health belief statements (Measure F) varied considerably.

\section{Relation With Personal Characteristics and Health Variables}

Table 4 presents relations of the CFC scale and underlying factors with several personal characteristics and health variables. Some are discussed in more detail here. We found no significant association between the CFC score and $\operatorname{sex} t(1991)=1.84, p=$ .07 , when we measured CFC using the 12-item CFC Scale. However, girls scored significantly higher on Factor A1 (and B1), $t(1991)=4.22, p<.01, d=0.19$, while boys scored significantly higher on Factor A3, $t(1991)=-6.50, p<.01, d=0.29$ and Factor $\mathrm{B} 2, t(1991)=-2.34, p=.02, d=0.10$. Pupils attending general secondary education scored significantly higher on the 12-item CFC Scale, $t(1971)=5.02, p<.01, d=0.23$. We found similar results for Factors A1, A2, and B2: $t(1971)=4.95, p<.01, d=0.22$; $t(1971)=4.60, p<.01, d=0.21$, and $t(1971)=3.19, p<.01, d=0.14$, respectively.

Adolescents with a religious upbringing scored higher on the 12-item CFC Scale, $t(1981)=5.36, p<.01, d=0.24$; Factor A1, $t(1981)=5.68, p<.01, d=0.26$; Factor A2, $t(1981)=2.64, p<.01, d=0.12$, and Factor $\mathrm{B} 2, t(1981)=2.82, p<.01$, $d=0.13$. The strength of these relationships is, however, predominantly limited.

Respondents with a worrying dependent attitude about their health lifestyle scored significantly higher on the 12-item CFC Scale and on all underlying factors except for Factor A3.

Investigation of the relation between $\mathrm{CFC}$ and all Big Five personality dimensions revealed that a positive loading on any of the five personality dimensions was associated with a significantly higher score on the 12-item CFC Scale: neuroticism, $t(1735)=2.04, p=.04, d=0.10$; extraversion, $t(1735)=2.43, p=.02$, $d=0.12$; openness to experience, $t(1735)=4.56, p<.01, d=0.22 ;$ conscientiousness, $t(1735)=5.90, p<.01, d=0.28 ;$ agreeableness, $t(1735)=3.78, p<.01$, $d=0.18$. We found different results for the underlying factors. We found significant associations between positive personality-factor loaders and all underlying factors for only two dimensions, openness to experience and conscientiousness.

\section{DISCUSSION}

The main goal of the present study was to provide additional evidence in the factor validation process of the CFC Scale, which measures "the intrapersonal struggle between present behavior with one set of immediate outcomes and one set of future outcomes" (Strathman et al., 1994, p.743). Even though this scale has not been extensively validated so far, it has already been used in a large variety of studies. To 


\section{TABLE 4. Relation of the Consideration Future Consequences Scale With Personal Characteristics and Health Variables}

\begin{tabular}{|c|c|c|c|c|c|c|c|c|}
\hline \multirow[b]{2}{*}{ Variable } & \multirow{2}{*}{\multicolumn{2}{|c|}{ Category }} & \multirow{2}{*}{$\begin{array}{l}\text { CFC } \\
\text { scale }\end{array}$} & \multicolumn{3}{|c|}{$\begin{array}{c}\text { Three-factor } \\
\text { structure }\end{array}$} & \multicolumn{2}{|c|}{$\begin{array}{l}\text { Two-factor } \\
\text { structure }\end{array}$} \\
\hline & & & & A1 & A2 & A3 & B1 & B2 \\
\hline \multirow[t]{2}{*}{ Sex } & \multirow{2}{*}{\multicolumn{2}{|c|}{$\begin{array}{l}\text { Girls } \\
\text { Boys }\end{array}$}} & 3.29 & $3.27^{* *}$ & 3.65 & $2.85^{* *}$ & $3.27^{* *}$ & $3.33^{*}$ \\
\hline & & & 3.25 & 3.15 & 3.59 & 3.08 & 3.15 & 3.39 \\
\hline \multirow[t]{2}{*}{ Education } & \multirow{2}{*}{\multicolumn{2}{|c|}{$\begin{array}{l}\text { Pre-vocational } \\
\text { General secondary }\end{array}$}} & $3.21^{* *}$ & $3.13^{* *}$ & $3.54^{* *}$ & 2.95 & $3.13^{* *}$ & $3.30^{* *}$ \\
\hline & & & 3.32 & 3.27 & 3.68 & 2.96 & 3.27 & 3.39 \\
\hline \multirow{2}{*}{$\begin{array}{l}\text { Body Mass } \\
\text { Index }\end{array}$} & \multicolumn{2}{|l|}{ Mean or lower } & 3.27 & 3.21 & 3.64 & 2.93 & 3.21 & 3.35 \\
\hline & \multicolumn{2}{|l|}{ Above mean } & 3.28 & 3.23 & 3.61 & 3.00 & 3.23 & 3.36 \\
\hline \multirow{5}{*}{$\begin{array}{l}\text { Attitude } \\
\text { about } \\
\text { health } \\
\text { lifestyle }\end{array}$} & \multicolumn{2}{|l|}{ Carefree sporty } & 3.26 & 3.18 & $3.64^{* *}$ & 2.96 & 3.18 & 3.37 \\
\hline & \multicolumn{2}{|l|}{ Worrying dependent } & $3.39^{* *}$ & $3.34^{* *}$ & $3.73^{* *}$ & 3.03 & $3.34^{* *}$ & $3.45^{* *}$ \\
\hline & \multicolumn{2}{|c|}{ Contended independent } & 3.20 & 3.15 & 3.52 & 2.86 & 3.15 & 3.26 \\
\hline & \multicolumn{2}{|l|}{ Looks over matter } & 3.27 & 3.21 & 3.60 & 2.99 & 3.21 & 3.36 \\
\hline & \multicolumn{2}{|l|}{ Indifferent solitary } & 3.03 & 2.96 & $3.30^{* *}$ & 2.88 & 2.96 & 3.13 \\
\hline \multirow[t]{2}{*}{ Happiness } & \multicolumn{2}{|l|}{ Mean or lower } & $3.22^{* *}$ & 3.18 & 3 & 2.93 & 3.18 & $3.29^{* *}$ \\
\hline & & & 3.30 & 3.23 & 3.66 & 2.98 & 3.23 & 3.39 \\
\hline \multirow[t]{10}{*}{ Personality $^{\mathrm{a}}$} & \multirow[t]{2}{*}{ Neuroticism } & $(+)$ & $3.31^{*}$ & 3.23 & 3.66 & $3.03^{* *}$ & 3.23 & $3.41^{* *}$ \\
\hline & & & 3.26 & 3.21 & 3.60 & 2.89 & 3.21 & 3.31 \\
\hline & \multirow[t]{2}{*}{ Extraversion } & $(+)$ & $3.31^{*}$ & 3.25 & 3.65 & $3.02^{* *}$ & 3.25 & $3.40^{*}$ \\
\hline & & $(-)$ & 3.25 & 3.20 & 3.61 & 2.90 & 3.20 & 3.33 \\
\hline & \multirow{2}{*}{$\begin{array}{l}\text { Openness to } \\
\text { experience }\end{array}$} & $(+)$ & $3.33^{* *}$ & $3.26^{* *}$ & $3.70^{* *}$ & $3.05^{* *}$ & $3.26^{* *}$ & $3.44^{* *}$ \\
\hline & & $(-)$ & 3.22 & 3.18 & 3.56 & 2.86 & 3.18 & 3.28 \\
\hline & \multirow[t]{2}{*}{ Conscientiousness } & $(+)$ & $3.35^{* *}$ & $3.30^{* *}$ & $3.69^{* *}$ & $3.01^{* *}$ & $3.30^{* *}$ & $3.42^{* *}$ \\
\hline & & $(-)$ & 3.21 & 3.14 & 3.57 & 2.90 & 3.14 & 3.30 \\
\hline & \multirow[t]{2}{*}{ Agreeableness } & $(+)$ & $3.32^{* *}$ & 3.24 & $3.73^{* *}$ & $3.00^{*}$ & 3.24 & $3.44^{* *}$ \\
\hline & & $(-)$ & 3.23 & 3.20 & 3.51 & 2.91 & 3.20 & 3.27 \\
\hline \multirow[t]{2}{*}{ Health status } & \multicolumn{2}{|l|}{ Mean or lower } & $3.20^{* *}$ & $3.14^{* *}$ & $3.54^{* *}$ & $2.91^{*}$ & $3.14^{* *}$ & $3.29^{* *}$ \\
\hline & \multicolumn{2}{|l|}{ Above mean } & 3.32 & 3.26 & 3.67 & 2.99 & 3.26 & 3.40 \\
\hline \multirow{2}{*}{$\begin{array}{l}\text { Religious } \\
\text { upbringing }\end{array}$} & Yes & & $3.31^{* *}$ & $3.26^{* *}$ & $3.64^{* *}$ & 2.98 & $3.26^{* *}$ & $3.38^{* *}$ \\
\hline & No & & 3.17 & 3.08 & 3.55 & 2.90 & 3.08 & 3.29 \\
\hline
\end{tabular}

Note. $n$ ranges from 1821 to 1994

${ }^{a}$ Positive versus negative personality-factor loaders.

$* p<.05$. ** $p<.01$.

provide further insight into the validity of the CFC scale, we examined the factor structure of the CFC Scale. Like Petrocelli (2003), the present study found evidence for a multiple factor solution. In addition, the results presented above give an indication of the convergent validity of the CFC Scale and the extent to which several personal characteristics, including sex, have discriminative power. The examination of the relationships between CFC and several health variables produced mixed results. 


\section{Factor Analysis}

Confirmatory factor analysis demonstrated that both the Strathman et al. (1994) and Petrocelli (2003) solutions do not provide an adequate fit of the data. Subsequent exploratory factor analysis provided evidence for a three-factor solution: a Factor A1 consisting of all seven reverse-scored items; and a clustering of positively worded items into two factors, Factor A2 (Item 6, 7, and 8) and Factor A3 (Item 1 and 2).

The first factor from the present study is almost identical to Factor 1 reported by Petrocelli (2003). However, Petrocelli added Item 2, a non-reverse-scored item, to this first factor. Although Petrocelli attained good internal consistency for his Factor 1, a closer look at the content of these items does not provide much support for the choice to retain this single non-reverse-scored Item 2 together with seven reverse-scored items in Factor 1, especially considering that the difference between the two factor loadings of Item 2 in the Petrocelli study was negligible. The results of the present study also contradict Petrocelli's choice of including Item 2 in Factor 1. The correlations found in the present study between Factor A1 and other measures of appreciation and expectations of the future, though modest in size, seem to confirm that Factor A1 is related to a more general future time concept.

The exploratory factor analysis also distinguished two mainly futureoriented factors, Factor A2 and Factor A3. The absence of multiple loadings on these factors and the presence of high factor loadings suggest that the positively worded items may represent two different aspects of future time perspective. Despite this clear statistical difference between the two factors, examination of the content of the items, however, suggests that it seems rather precarious to pursue this distinction. What is more, the stability in terms of internal consistency of both factors was modest, which seems to indicate that the factors do not represent two independently relevant aspects of the CFC construct. The convergent validity tests and the relation with personal characteristics and health variables showed that the combined Factor B2 accounts for most of the relations found for Factors A2 and/or A3. Future research must clarify whether a two-factor structure, distinguishing the reverse-scored items from the non-reverse-scored items, is indeed a more appropriate solution. The correlation among the three factors was low despite the fact that they all consist of items included in the 12-item CFC Scale. This suggests that the Factors A1, A2, and A3 may be measuring more than one construct.

\section{Relation Between Sex and CFC}

Several researchers have demonstrated that time perspective and sex are associated (Zimbardo \& Boyd, 1999; Zimbardo, Keough, \& Boyd, 1997). Men tend to score higher on measures of present time perspective, while women tend 
to report higher future time perspective scores. In accordance with these findings, Petrocelli (2003) reported that women scored significantly higher on the 12-item CFC Scale and Factor 1, while there were no sex differences in Factor 2. In the present study, no sex differences were observed in the 12-item CFC Scale, which is similar to previous studies using the CFC Scale. However, girls scored higher on Factor A1/B1, and boys higher on Factor B2 and Factor A3. In other words, girls show a higher CFC when the construct is framed in present-oriented statements, and boys when it is framed in future-oriented statements. This provides further indication that the factors underlying the CFC Scale may be measuring different CFC constructs. More positively, given the fairly similar convergent validity of the CFC Scale and the underlying factors, one might conclude that the CFC scale measures different aspects of one broader construct. However, regardless of where the line between constructs and aspects of constructs is drawn-a question that might be answered in future research - the important conclusion from these findings is that the underlying factors explain different aspects of (health) behavior and, therefore, their distinction is important.

\section{Construct Validity of the CFC Scale}

Petrocelli (2003) argued that a short version of the 12-item CFC Scale, consisting of the eight items loading on Factor 1, might be a more appropriate measure of the CFC construct. The evidence presented in this study suggests that if this short version of the CFC Scale were indeed a better measure of the CFC construct, it would be most appropriate to use the reverse-scored items exclusively. Statistically, the 12-item CFC Scale and Factor A1/B1 from this study perform similarly as a measure of the CFC construct. In addition, in terms of internal consistency, the reliability of the 12-item CFC Scale and Factor A1/B1 are highly comparable. Inclusion of the five non-reverse-scored items does not substantially improve the reliability of the CFC Scale, while omission of these items makes it more efficient. The results provide additional supporting evidence with regard to the convergent validity of both the 12-item CFC Scale and Factor A1/B1.

Although intuitively appealing, others have already suggested that it is incorrect to assume that scoring low on a present-oriented scale automatically indicates being future-oriented (Petrocelli, 2003; Zimbardo \& Boyd, 1999). Indeed, Petrocelli claimed that if an individual states that they are not influenced by the immediate outcomes, it does not mean that they are influenced by the distant consequences of current behavior. If this is true, summing up the reversescored items and the positively worded items would be nonsensical. Then, the short version of the CFC Scale would assess a more present-oriented aspect of the CFC construct, which differs from what was originally proposed by Strathman et al. (1994). In this context, Petrocelli argued that "it might be more appropriate to consider the CFC Scale as indicating the extent to which an individual is not influenced primarily by the immediate consequences of behavior" 
(2003, p. 411). The repeated result that the more present-oriented statements are the most dominant and consistent part of the 12-item CFC Scale in any case appears to implicate the construct validity of the 12-item CFC Scale.

Furthermore, the findings from the present study suggest that it could be inappropriate to completely exclude Factors A2 and A3 (or B2), despite their modest internal consistency. Convergent validity was more or less equally provided for all factors, and the relations of Factors A2 and A3 (or B2) with personal characteristics and health variables suggest they pick up part of the CFC construct. In part, the Factors A2 and A3 (or B2) seem complementary to Factor A1/B1, as they account for something the 12-item CFC Scale picks up, but Factor A1/B1 does not (or, as in the case of sex, pick up opposite effects that cancel out in the 12-item CFC-scale). This is, for instance, the case with happiness and the personality dimensions neuroticism, extraversion, and agreeableness. But most of the time, Factors A2 and A3 (or B2) show similar relations as Factor A1/B1. It would be instructive to examine the content of Factors A2 and A3 (or B2) in more detail in future research.

\section{Temporal Discounting}

In the present study we used, among other approaches, temporal discounting as a measure of time preference. It is important to note that there are several mathematical methods to measure discount rates (e.g., Green, Myerson, \& Ostaszewski, 1999; Myerson, Green, \& Warusawitharana, 2001; DiClemente \& Hantula, 2003; Schoenfelder \& Hantula, 2003). We used a hyperbolic-like model that uses an empirically derived parameter value of time preference often denoted as $k$. Using a continuous form of $k$, rather than the ordinal form of $k$ we used, yields very similar correlations with the CFC scale and underlying factors. Recently, a potentially valuable alternative labeled "area-under-the-curve" (AUC) has come to the forth (see, Myerson et al., 2001). This theoretically neutral approach measures time preference as the area under the empirical discounting curve and so avoids making any assumptions about the mathematical form of the discounting curve (Green \& Myerson, 2004). AUC has been used, for example, in studies concerned with discounting in relation to individual competitive ability (Critchfield \& Atteberry, 2003) and discounting by pathological gamblers (Dixon, Marley, \& Jacobs, 2003). We investigated whether using the AUC approach altered our findings, regarding correlations between temporal discounting and the CFC Scale and/or underlying factors. The mean AUC value was .48 and Spearman's rank-order correlations between AUC and the CFC Scale, Factor A1/B1, Factor A2, Factor A3, and Factor B2, were .16, .15, .09, .06, and .10, respectively. All correlations were significant at $p<.01$, except for AUC and Factor A3 (significant at $p<.05$ ). These correlations were very similar to the correlations found between the CFC Scale and underlying factors and the computed discount rate when trade-offs were pictured at 5 years from now. Moreover, the 
structure of the magnitude of the associations across the CFC Scale and underlying factors was almost identical for all discount rate measures. This supports the validity of our findings.

\section{Strength and Limitations of the Study}

A shortcoming of previous research concerned with the factor validation of the CFC Scale was the academic setting in which the CFC Scale was administered. The present study provides evidence of the factor structure in a non-academic setting. The respondents in this and Strathman et al.'s (1994) study differ in many aspects. The Strathman study sample consisted of American college students in the early 1990s, while we report on a recent sample of Dutch secondary school pupils between the ages of 11 and 15. When we compare the mean CFC scores found in these studies - as well as those reported in recent studies by Petrocelli (2003), who used a sample of American undergraduate students, and Rappange (2005), who used a sample of Dutch college students-it seems that the differences between respondents in terms of age, educational level, and time period of study have little effect on CFC scores. The same seems to apply to the possible effect of cultural differences between the samples. As supporting evidence, previous research has shown that differences in long-term orientation between the Americans and the Dutch are marginal (Hofstede, 1991; www.geert-hofstede.com). It is, however, not possible to say how these differences in age, educational level, time period of study, and culture may affect the factor structure of the CFC Scale.

However, it would be inappropriate to pass by to the widely spread notion of immaturity of judgment of young adolescents and their ignorance in foreseeing future consequences. Given our sample, the participants may be presumed a priori to be more present-oriented, which might have blurred the scores on the more future-oriented statements. The results with regard to the feasibility of the CFC Scale in the present study and the mean CFC score provide encouraging evidence that the alleged immaturity of the participants did not influence the findings too much. In future research, the CFC Scale should preferably be administered in a general population. Another limitation of this study is that participants were asked to complete a translated and somewhat simplified version of the CFC Scale in order to make it more suitable for young adolescents. Although this was done with utmost care, the influence on the measurement of CFC is unknown. Finally, in the "Health \& Future" questionnaire, the 12 items of the CFC Scale were administered in the same order for the whole population. As far as we know, this is common in research using the CFC Scale. However, the split we found in the factor structure of the CFC regarding the futureoriented statements-i.e., Items 1 and 2 in Factor A3 versus Items 6, 7, and 8 in Factor A2 - raises the question of whether the order and clustering of items may influence participants' response and therewith on the factor structure. Future studies might consider presenting the statements in a different order. 


\section{CFC in Health Care Research}

Though the CFC Scale consists of general statements about the CFC, this has not restrained researchers from using the scale in healthcare research. The current analysis was conducted on a dataset from a previous study concerned with adolescents' behavior in relation to attitudes about their health lifestyle and their consideration of future consequences in their health behavior. Although not every result is completely independent of how we used the CFC Scale, we found that CFC was significantly related to adolescents' attitudes about health lifestyle, happiness, and health status, but not to Body Mass Index. Moreover, the significant relationships between CFC and the health investments and some of the health belief statements used to provide convergent validity, suggest that CFC is also useful when the consequences of behavior are related to health issues. Nevertheless, in most cases, the strength of the relationships was small. The lack of consistent results and the modest strength of the significant relationships should be reckoned when using the CFC Scale in health care research.

In summary, the present findings confirm the evidence for a multiple factor structure underlying the 12-item CFC Scale. The current study helped make the content and shape of the first factor more evident and showed once more that this present-oriented factor is producing results similar to the 12-item CFC Scale. However, it remains unclear how many factors the remaining future-oriented items represent and what these items actually reflect. These are important considerations for future research.

\section{AUTHOR NOTES}

David R. Rappange is a researcher at the Department of Health Policy \& Management and the Institute for Medical Technology Assessment of the Erasmus Medical Center. His main research interests include individual (health) behaviors, preferences, and expectations, as well as the economic and societal valuation of prevention. Werner B. F. Brouwer is a professor of Health Economics at the Department of Health Policy \& Management and the Institute for Medical Technology Assessment of the Erasmus Medical Center. His main research interest is the methodology of economic evaluation in healthcare. Other research interests include the optimal rules for discounting future costs and effects. N. Job A. van Exel is a senior researcher at the Department of Health Policy \& Management and the Institute for Medical Technology Assessment of the Erasmus Medical Center. His main research interests include valuations methods and individual (health) behaviors, preferences, and expectations.

\section{REFERENCES}

Bartlett, M. S. (1950). Tests of significance in factor analysis. British Journal of Psychology (Statistical Section), 3, 77-85.

Catell, R. B. (1966). The scree test for the number of factors. Multivariate Behavioral Research, 1, 245-276.

Cauffman, E., \& Steinberg, L. (2000). (Im)maturity of judgment in adolescence: Why adolescents may be less culpable than adults. Behavioral Sciences and the Law, 18, 741-760. 
Cohen, J. (1988). Statistical power analysis for the behavioral sciences. Hillsdale, NJ: Erlbaum.

Critchfield, T. S., \& Atteberry, T. (2003). Temporal discounting predicts individual competitive success in a human analogue of group foraging. Behavioural Processes, 64, 315-331.

DeVolder, M. L., \& Lens, W. (1982). Academic achievement and future time perspective as a cognitive-motivational concept. Journal of Personality and Social Psychology, 42, 566-571.

DiClemente, D. F., \& Hantula, D. A. (2003). Optimal foraging online: Increasing sensitivity to delay. Psychology and Marketing, 20, 785-809.

Dixon, M. R., Marley, J., \& Jacobs, E. A. (2003). Delay discounting by pathological gamblers. Journal of Applied Behavior Analysis, 36 449-458.

Dorr, N., Krueckeberg, S., Strathman, A., \& Wood, M. D. (1999). Psychosocial correlates of voluntary HIV antibody testing in college students [Abstract]. AIDS Education and Prevention, 11, 14-27.

Essink-Bot, M. L., Krabbe, P. F. M., Bonsel, G. J., \& Aaronson, N. K. (1997). An empirical comparison of four generic health measures: The Nottingham-Health Profile, the Medical Outcomes Study 36-Item Short-Form Health Survey, the COOP/WONCA Charts, and the EuroQol Instrument. Medical Care, 35, 522-537.

Field, A. (2005). Discovering statistics using SPSS (2nd ed.). London: Sage Publications.

Fraisse, P. (1963). The psychology of time. (J. Leith, Trans.). Westport, CT: Greenwood Press.

Frank, L. K. (1939). Time perspectives. Journal of Social Philosophy, 4, 293-312.

Gerris, J. R. M., Houtmans, M. J. M, Kwaaital-Roosen, E. M. G., Schipper, J. C., Vermulst, A. A., \& Janssens, J. M. A. M. (1998). Parents, adolescents and young adults in Dutch families: A longitudinal study. The Netherlands: University of Nijmegen, Institute of Family Studies.

Goldberg, L. R. (1992). The development of markers for the Big-Five factor structure. Psychological Assessment, 4, 26-42.

Gonzalez, A., \& Zimbardo, P. G. (1985). Time in perspective: A Psychology Today survey report. Psychology Today, 19, 21-26.

Green, L., \& Myerson, J. (2004). A discounting framework for choice with delayed and probabilistic rewards. Psychological Bulletin, 130, 769-792.

Green, L., Myerson, J., \& Ostaszewski, P. (1999). Amount of reward has opposite effects on the discounting of delayed and probabilistic outcomes. Journal of Experimental Psychology: Learning, Memory, and Cognition, 25 418-427.

Hofstede, G. H. (1991). Cultures and organizations: software of the mind. London: McGraw-Hill.

Horn, J. L. (1965). A rationale and test for the number of factors in factor analysis. Psychometrika, 30, 179-185.

Insko, C. A., Schopler, J., Gaertner, L., Wildschut, T., Kozar, R., Pinter, B., et al. (2001). Interindividual-intergroup discontinuity reduction through the anticipation of future interaction. Journal of Personality and Social Psychology, 80, 95-111.

Insko, C. A., Schopler, J., Pemberton, M. B., Wieselquist, J., McIlraith, S. A., Currey, D. P., et al. (1998). Long-term outcome maximization and the reduction of interindividualintergroup discontinuity. Journal of Personality and Social Psychology, 75, 695-710.

Joireman, J. A. (1999). Additional evidence for validity of the Consideration of Future Consequences Scale in an academic setting. Psychological Reports, 84, 1171-1172.

Joireman, J., Anderson, J., \& Strathman, A. (2003). The aggression paradox: Understanding links among aggression, sensation seeking, and the consideration of future consequences. (2003). Journal of Personality and Social Psychology, 84, 1287-1302.

Joireman, J. A., Lasane, T. P., Bennett, J., Richards, D., \& Solaimani, S. (2001). Integrating social value orientation and the consideration of future consequences within the extended norm activation model of proenvironmental behaviour. British Journal of Social Psychology, 40, 133-155. 
Joireman, J., Sprott, D. E., \& Spangenberg, E. R. (2005). Fiscal responsibility and the consideration of future consequences. Personality and Individual Differences, 39, 1159-1168.

Joireman, J. A., Van Lange, P. A. M., \& Van Vugt, M. (2004). Who cares about the environmental impact of cars? Those with an eye toward the future. Environment and Behaviour, 36, 187-206.

Kaiser, H. F. (1960). The application of electronic computers to factor analysis. Educational and Psychological Measurement, 20, 141-151.

Kaiser, H. F. (1970). A second generation Little Jiffy. Psychometrika, 35, 401-415.

Kaiser, H. F. (1974). An index of factorial simplicity. Psychometrika, 39, 31-36.

Kaser-Boyd, N., Adelman, H. S., \& Taylor, L. (1985). Minors' ability to identify risks and benefits of therapy. Professional Psychology: Research and Practice, 16, 411-417.

Kastenbaum, R. (1961). The dimension of future time perspective: An experimental analysis. Journal of General Psychology, 65, 203-128.

Lamm, H., Schmidt, R. W., \& Trommsdorff, G. (1976). Sex and social class as determinants of future orientation in adolescents. Journal of Personality and Social Psychology, 34, 314-326.

Lewin, K. (1942). Time perspective and morale. In G. Lewin (Ed.), Resolving social conflicts (pp. 103-124). New York: Harper.

Lewis, C. C. (1981). How adolescents approach decisions: Changes over grades seven to twelve and policy implications [Abstract]. Child Development, 52, 538-544.

Lindsay, J. J., \& Strathman, A. (1997). Predictors of recycling behavior: An application of a modified health belief model [Abstract]. Journal of Applied Social Psychology, 27, 1799-1823.

Mann, L., Harmoni, R., \& Power, C. (1989). Adolescent decision-making: The development of competence. Journal of Adolescence, 12, 265-278.

Myerson, J., Green, L., \& Warusawitharana, M. (2001). Area under the curve as a measure of discounting. Journal of the Experimental Analysis of Behavior, 76 235-243.

Nuttin, J. (1964). The future time perspective in human motivation and learning. Acta Psychologica, 23, 60-82.

Orbell, S., \& Hagger, M. (2006). Temporal framing and the decision to take part in Type 2 diabetes screening: Effects of individual differences in consideration of future consequences on persuasion. Health Psychology, 25, 537-548.

Orbell, S., Perugini, M., \& Rakow, T. (2004). Individual differences in sensitivity to health communications: Consideration of future consequences. Health Psychology, 23, 388-396.

Petrocelli, J. V. (2003). Factor validation of the Consideration of Future Consequences Scale: Evidence for a short version. Journal of Social Psychology, 143, 405-413.

Pett, M. A., Lackey, N. R., \& Sullivan, J. J. (2003). Making sense of factor analysis: The use of factor analysis for instrument development in health care research. Thousand Oaks, CA: Sage Publications.

Quadrel, M. J., Fischhoff, B., \& Davis, W. (1993). Adolescent (in)vulnerability. American Psychologist, 48, 102-116.

Rappange, D. R. (2005). Leefstijl van studenten: Een onderzoek naar leefstijlverschillen tussen thuiswonende en uitwonende studenten [Students' lifestyle: A study of lifestyle differences between students who live at home and students who live away from home]. Unpublished bachelor's thesis, Erasmus MC, Rotterdam, the Netherlands.

Schoenfelder, T. E., \& Hantula, D. A. (2003). A job with a future? Delay discounting, magnitude effects, and domain independence of utility for career decisions. Journal of Vocational Behavior, 62, 43-55.

Steinberg, L., \& Cauffman, E. (1996). Maturity of judgement in adolescence: Psychosocial factors in adolescent decision-making. Law and Human Behaviour, 20, 249-272.

Strathman, A., Gleicher, F., Boninger, D. S., \& Edwards, C. S. (1994). The consideration of future consequences: Weighting immediate and distant outcomes of behavior. Journal of Personality and Social Psychology, 66, 742-752. 
Tabachnick, B. G., \& Fidell, L. S. (2001). Using multivariate statistics (4th ed.). New York: Allyn \& Bacon.

Van Exel, N. J. A., De Graaf, G., \& Brouwer, W. B. F. (2006). "Everyone dies, so you might as well have fun!" Attitudes of youths about their health lifestyle. Social Science and Medicine, 63, 2628-2639.

Van Exel, N. J. A., Koolman, X., De Graaf, G., \& Brouwer, W. B. F. (2006). Overweight and obesity in Dutch adolescents: Associations with health lifestyle, personality, social context and future consequences: Methods \& tables (Rep. No. 06.82). Retrieved October 2, 2006, from Erasmus MC, institute for Medical Technology Assessment Web site: http://www.imta.nl/publications/0682.pdf

Wallace, M. (1956). Future time perspective in schizophrenia. Journal of Abnormal and Social Psychology, 52, 240-245.

Watkins, M. W. (2000). Monte carlo PCA for parallel analysis [Computer software, available at http://www.personal.psu.edu/mww10/Watkins3.html]. State College, PA: Ed \& Psych Associates.

Wheaton, B., Muthen, B., Alwin, D. F., \& Summers, G. F. (1977). Assessing reliability and stability in panel model. In D. R. Heise (Ed.), Sociological methodology 1977 (pp. 84-136). San Francisco: Jossey-Bass.

Zimbardo, P. G. (1990). The Stanford time perspective inventory. Stanford, CA: Stanford University.

Zimbardo, P. G., \& Boyd, J. N. (1999). Putting time in perspective: A valid, reliable individualdifferences metric. Journal of Personality and Social Psychology, 77, 1271-1288.

Zimbardo, P. G., Keough, K. A., \& Boyd, J. N. (1997). Present time perspective as a predictor of risky driving. Personality and Individual Differences, 23, 1007-1023.

Zwick, W. R., \& Velicer, W. F. (1986). Comparison of five rules for determining the number of components to retain. Psychological Bulletin, 99, 432-442.

Received September 7, 2007

Accepted May 13, 2008

\section{APPENDIX}

Consideration of Future Consequences Scale: Dutch Version for Young Adolescents [in English]

\begin{tabular}{|lllll|}
\hline \hline \multicolumn{5}{c|}{ Do the following statements fit you? } \\
\hline 1 & 2 & 3 & 4 & 5 \\
\hline not at all & not & a little & well & extremely well \\
\hline
\end{tabular}

1. I think about what my life might be like in the future and try to improve my future with the things I do now.

2. I often do things that might only give me pleasure in the long run. 


\section{APPENDIX (Continued)}

3. I only do things that I enjoy and do not worry about what may happen later on.

4. I only do things that give me pleasure right away.

5. I prefer choosing the line of least resistance.

6. I am willing to do something I find not much fun if it pays off later on.

7. I think it is important to know whether things could have negative consequences, even though you may not find out these consequences for a long time.

8. I think it is better to do something that is very important for the future than something that has a little bit importance for now.

9. Some things could have negative consequences in the long run, but I do not worry too much about that. I will resolve things before they get too bad.

10. I think sacrificing now because of possible future consequences is unnecessary. I can deal with future consequences later on.

11. I only do things that I enjoy at this moment. I will resolve any future problems when they occur.

12. Because the outcomes of my behavior now are clear, they are more important to me than possible distant outcomes. 
Copyright of Journal of Social Psychology is the property of Taylor \& Francis Ltd. and its content may not be copied or emailed to multiple sites or posted to a listserv without the copyright holder's express written permission. However, users may print, download, or email articles for individual use. 